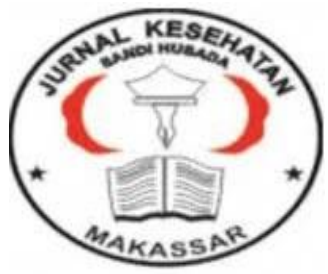

\author{
Jurnal Ilmiah Kesehatan Sandi Husada
}

hhttps://akper-sandikarsa.e-journal.id/JIKSH

Volume 9, Nomor 2, Desember 2020, pp 853-859

p-ISSN: 2354-6093 dan e-ISSN: 2654-4563

DOI: $10.35816 /$ jiskh.v10i2.422

\title{
Hubungan Pengetahuan dengan Perilaku Merokok Pada Siswa SMK Negeri Tanjungsari Lampung Selatan
}

The Relationship between Knowledge and Smoking Behavior in Vocational School Students of Tanjungsari South Lampung

\author{
Zainul Umari' ${ }^{1}$, Nopi Sani ${ }^{2}$, Tusy Triwahyuni ${ }^{3}$, Rina Kriswiastiny ${ }^{4}$ \\ ${ }^{1}$ Mahasiswa Program Studi Kedokteran Universitas Malahayati \\ ${ }^{2}$ Staf Pengajar Fakultas Kedokteran Universitas Malahayati \\ ${ }^{3}$ Departemen Parasitologi Fakultas Kedokteran Universitas Malahayati \\ ${ }_{4}^{4}$ Departemen Ilmu Penyakit Dalam Rumah Sakit Pertamina Bintang Amin
}

Artikel info

Artikel history:

Received; Agustus 2020

Revised;September 2020

Accepted;September2020

\begin{abstract}
Abstrak
Latar Belakang: merokok merupakan salah satu kegiatan yang masih dilakukan individu dalam segala usia mulai dari anak-anak hingga dewasa dan tidak menutup kemungkinan untuk mereka yang sebelumnya sudah merokok, kemudian merokok kembali, ataupun bagi mereka yang sebelumnya belum pernah mencoba merokok pun menjadi tertarik untuk mencobanya. Perlahan seperti air, mereka selalu memiliki alasan untuk merokok. Prevalensi perokok aktif di Indonesia meningkat sangat cepat. Apabila pemerintah tidak sigap dengan kebijakan yang lebih efektif, diperkirakan pada tahun 2025 jumlah perokok di Indonesia akan bertambah sebanyak 90 juta orang. Tujuan penelitian: Untuk mengetahui hubungan antara pengetahuan dengan perilaku merokok pada siswa SMK Negeri Tanjungsari Lampung Selatan. Metode penelitian: Penelitian ini menggunakan rancangan cross sectional, data yang digunakan dalam penelitian ini adalah data primer yang diambil dari kuesioner. Jumlah sampel 78 responden, data dianalisis menggunakan uji fisher's exact test dengan tingkat kemaknaan $\rho$ value $<0,05$. Hasil penelitian: Hasil penelitian menunjukkan bahwa dari 78 responden terdapat 15 responden pengetahuan kurang dengan perilaku merokok (93,8\%) dan 1 responden pengetahuan kurang dengan perilaku tidak merokok (6.3\%). Kemudian siswa dengan pengetahuan baik dengan perilaku merokok terdapat 39 responden (62,9\%) dan pengetahuan baik dengan perilaku tidak merokok terdapat 23 responden (37,1\%). Kesimpulan: Hasil penelitian terdapat hubungan yang bermakna antara pengetahuan dan perilaku merokok di SMK Negeri Tanjungsari Lampung Selatan. Melakukan
\end{abstract}


sosialisasi terhadap sekolah-sekolah tentang bahaya merokok dengan memberikan edukasi kepada siswa tentang dampak dari perilaku merokok, lebih ditujukan supaya siswa yang merokok agar berhenti dari kebiasaan merokok.

\begin{abstract}
Background: smoking is an activity that is still carried out by individuals at all ages ranging from children to adults and does not rule out those who have previously smoked, then smoke again, or those who have never tried smoking before become interested in try it. Slowly like water, they always have an excuse to smoke. The prevalence of active smoking in Indonesia is increasing very rapidly. If the government is not alert to more effective policies, it is estimated that by 2025 the number of smokers in Indonesia will increase by 90 million people. The research objective: To determine the relationship between knowledge and smoking behavior in students of SMK Negeri Tanjungsari, South Lampung. Methods: This study used a cross-sectional design, the data used in this study were primary data taken from a questionnaire. The number of samples was 78 respondents, the data were analyzed using the fisher's exact test with a significance level of $\rho$ value $<0.05$. Results: The results showed that of the 78 respondents there were 15 respondents who lacked knowledge of smoking behavior (93.8\%) and respondent knowledge less with non-smoking behavior (6.3\%). Then there were 39 students with good knowledge of smoking behavior (62.9\%) and 23 respondents (37.1\%) with good knowledge of non-smoking behavior. Conclusion: The results of this study have a significant relationship between smoking knowledge and behavior at SMK Negeri Tanjungsari, South Lampung. socializing to schools about the dangers of smoking by providing education to students about the impact of smoking behavior, aimed more so that students who smoke stop smoking
\end{abstract}

Keywords:

Smoking;

Knowledge;

Adolescents;
Coresponden author:

Email: zainulumari669@gmail.com

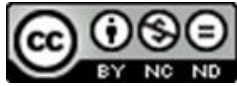

artikel dengan akses terbuka dibawah lisensi CC BY NC ND 4.0

\title{
Pendahuluan
}

Merokok merupakan salah satu kegiatan yang masih dilakukan individu dalam segala usia mulai dari anak-anak hingga dewasa dan tidak menutup kemungkinan untuk mereka yang sebelumnya sudah merokok, kemudian merokok kembali, ataupun bagi mereka yang sebelumnya belum pernah mencoba merokok pun menjadi tertarik untuk mencobanya. Perlahan seperti air, mereka selalu memiliki alasan untuk merokok (Aulia, dalam el hasna, 2017). Persentase penduduk dunia yang mengkonsumsi tembakau didapatkan sebanyak 57\% pada penduduk Asia dan Australia, 14\% pada penduduk Eropa Timur dan pecahan Uni Soviet, 12\% penduduk Amerika, 9\% penduduk Eropa Barat, dan 8\% pada penduduk Timur Tengah serta Afrika. Sementara itu ASEAN merupakan sebuah kawasan dengan 
$10 \%$ dari seluruh perokok dunia dan $20 \%$ penyebab kematian global akibat tembakau, dan Indonesia merupakan negara dengan persentase perokok tertinggi di kawasan ASEAN yaitu 46,16\% (Kemenkes RI, 2015).

Hasil Riset Kesehatan Dasar (Riskesdas) pada tahun 2018 menyatakan bahwa perilaku merokok penduduk Indonesia di usia 15 tahun keatas, sebesar 33,8\% pada tahun 2018. Perokok pada usia lebih dari 10 tahun didapati sebesar 24,3\% merokok setiap harinya, akan tetapi sebesar 4,6\% merokok dengan kurun waktu yang tergolong jarang. Dan proporsi kelompok umur 10 - 14 tahun sebesar 0,7\%, 15 - 19 tahun sebesar 12,7\% dan 20 - 24 tahun sebesar 27,3\% yang merupakan perokok aktif dengan merokok setiap harinya. Dengan persentase laki-laki sebesar 47,3\% dan perempuan sebesar 1,2\%. Sedangkan rerata proporsi perokok setiap hari di provinsi lampung sebesar $28,1 \%$ dan perokok kadang-kadang 3,6\% (Riskesdas, 2018).

Prevalensi perokok aktif di Indonesia meningkat sangat cepat. Apabila pemerintah tidak sigap dengan kebijakan yang lebih efektif, diperkirakan pada tahun 2025 jumlah perokok di Indonesia akan bertambah sebanyak 90 juta orang. Komnas Perlindungan Anak Indonesia (KPAI) Kota Jakarta menyebut jumlah perokok pemula meningkat hingga $45 \%$. KPAI juga berpendapat dengan keterjangauan membeli rokok dengan cukai yang murah menjadikan salah satu penyebab banyak perokok pemula di usia dini yang hampir $80 \%$ nya mulai merokok ketika usianya belum mencapai 19 tahun (el Hasna, 2017). Selain itu remaja yang merokok biasanya demi diterimanya dalam suatu kelompok teman sebaya, usia remaja merupakan usia yang masih memiliki emosi yang labil sehingga demi diterimanya dalam suatu kelompok teman sebaya ia akan melakukan apapun meskipun menyimpang (Anggarwati, 2014). Seperti yang diungkapkan Hurlock (2012) Sebagian besar remaja ingin diterima oleh teman-teman sebayanya, tetapi sering kali diperoleh dengan perilaku yang tidak bertanggung jawab salah satunya perilaku merokok. Sebagian besar masyarakat Indonesia masih menganggap merokok adalah perilaku yang wajar dalam kehidupan sosial. Generasi muda memiliki tingkat penyebaran yang tinggi menjadi perokok pemula, bahkan diwilayah tertentu merokok dimulai di usia balita. Dalam masyarakat juga dikenal kelompok rentan, yaitu kelompok dengan prevalensi tinggi sehingga memiliki kemungkinan yang besar melakukan tindakan merokok. Masyarakat rentan berhubungan dengan tingkat pendidikan, tingkat pengetahuan dan perilaku, terutama pemahaman bahaya merokok. Selain itu tingkat ekonomi keluarga khususnya keluarga miskin dan keluarga yang lebih memprioritaskan belanja rokok dibanding kebutuhan lainnya (kementerian kesehatan, 2012).

Pengetahuan masyarakat masih rendah. Meskipun telah terbukti dengan jelas tentang bahaya rokok, hanya sedikit dari perokok yang memahami bahwa merokok merugikan hampir setiap organ tubuh dan menyebabkan banyak penyakit. Kebanyakan mengira rokok hanya menyebabkan beberapa penyakit (Zaenabu, 2014). Kurangnya pengetahuan tentang bahaya merokok menjadi salah satu alasan remaja merokok (silowati, 2012). Hal tersebut sejalan dengan penelitian yang dilakukan oleh Jelantik dan Tjindawang (2013) di SMAN 5 Mataram bahwa terdapat hubungan yang bermakna antara pengetahuan remaja tentang rokok dengan kebiasaan merokok. Penelitian Andika (2016) Hubungan Pengetahuan Dengan Kejadian Merokok Pada Pelajar SMPN 1 Pariaman, menunjukkan hasil penelitian pada 228 orang didapatkan responden dengan tingkat pengetahuan baik sebesar $60 \%$ dan kejadian merokok sebesar 1\%. Analisis statistik menunjukkan bahwa terdapat hubungan antara tingkat pengetahuan tentang rokok dan kejadian merokok pada pelajar SMPN 1 Pariaman. Sedangkan hasil zaenabu (2014) hubungan pengetahuan tentang bahaya rokok dengan tindakan merokok pada siswa negeri 8 surakarta menunjukkan tidak ada Hubungan bermakna antara Pengetahuan tentang bahaya rokok 
dengan tindakan merokok. Dalam penelitian yang dilakukan andriyani (2018) menemukan didapat hasil bahwa siswa yang merokok di SMK Negeri 2 bandar lampung sebesar 10\% dan siswa yang merokok di SMK 2 mei bandar lampung sebesar 40\%. Dari hasil survei awal di SMKN Tanjungsari Lampung Selatan, melalui wawancara dengan beberapa orang siswa diketahui bahwa perilaku merokok masih banyak dijumpai pada remaja di lingkungan sekolah karena remaja beranggapan bahwa merokok melambangkan kejantanan bagi seorang pria. Hal ini didukung dari hasil wawancara dengan guru Bimbingan Konseling yakni terdapat 60\% siswa yang merokok dan pada tahun ajaran 2019/2020 telah ditemukan tercatat sebanyak 13 kasus siswa yang merokok di lingkungan sekolah. Letak sekolah yang dekat dengan pemukiman masyarakat dan di tambah lagi dengan tempat olah raga yang terpisah dari sekolah seperti lapangan sepak bola sehingga jauh dari pantauan guru. Oleh sebab itu peneliti tertarik untuk meneliti hubungan pengetahuan dengan perilaku merokok pada siswa SMK Negeri Tanjungsari Lampung Selatan tahun 2019/2020.

\section{Metode}

Desain penelitian yang digunakan pada penelitian ini bersifat analitik observatif, yaitu mencari hubungan antara variabel bebas dan variabel terikat, dengan pendekatan cross sectional yang digunakan dalam satu waktu. Penelitian dilaksanakan pada bulan Maret 2020 di SMK Negeri Tanjungsari Kabupaten Lampung Selatan. Populasi dalam penelitian ini adalah seluruh siswa kelas X dan XI SMK N Tanjungsari Lampung Selatan yang berjumlah 316 siswa. Teknik sampling yang digunakan dalam penelitian ini adalah teknik simple random sampling dengan prosedur pengambilan sampel dilakukan dengan cara undian. Untuk jumlah sampel pada penilitan ini sebanyak 78 sampel. Pengumpulan data dalam penelitian ini dilakukan dengan cara melalui wawancara langsung menggunakan kuisioner serta observasi dokumen yang ada di Sekolah. Analisis data yang dilakukan pada penelitian ini meliputi analisis univariat dan analisis bivariat. Analisis bivariat diuji menggunakan uji statistik Chi square dan jika tidak memenuhi syarat uji tersebut, maka uji yang dipakai adalah fisher's exact test untuk menguji perbedaan proporsi atau persentase antara beberapa kelompok data. Tujuannya adalah untuk mengetahui hubungan antara variabel independen kategorik dengan variabel dependen kategorik.

\section{Hasil Dan Pembahasan}

Tabel 1. Distribusi Frekuensi Karakteristik Pada siswa SMK Negeri Tanjungsari Lampung Selatan 2020

\begin{tabular}{cccc}
\hline Usia & Frekuensi & Persentase (\%) \\
& 15 Tahun & 12 & 15,4 \\
& 16 Tahun & 46 & 59,0 \\
& 17 Tahun & 17 & 21.8 \\
18 Tahun & 3 & 3,8 \\
\hline Kelas & & & \\
& Kelas X & 37 & 47,4 \\
Kelas XI & 41 & 52,6 \\
\hline Mulai Merokok & & \\
< 15 Tahun & 42 & 15,8 \\
> 15 Tahun & 12 & 30,8 \\
Tidak Merokok & 24 & \\
\hline Alasan Merokok & &
\end{tabular}




\begin{tabular}{ccc} 
Rasa ingin tahu & 21 & 26,9 \\
Menghilangkan Stress & 17 & 12,8 \\
Terpaksa oleh & 1 & 1,8 \\
Teman/Lingkungan & & \\
Tidak Merokok & 24 & 30,8 \\
\hline Tipe Perokok & & \\
Ringan & 37 & 47,4 \\
Sedang & 17 & 21,8 \\
Tidak Merokok & 24 & 30,8 \\
\hline Lama Merokok & & \\
<6 Bulan & 2 & 2,6 \\
6-12 Bulan & 10 & 12,8 \\
>1 Tahun & 42 & 53,8 \\
Tidak Merokok & 24 & 30,8 \\
Kurang & & 20,5 \\
Baik & 16 & 79,5 \\
Total & 62 & $\mathbf{1 0 0 . 0}$ \\
Mengetahuan Bahaya Merokokok & $\mathbf{7 8}$ & 69,2 \\
Tidak Merokok & & 30,8 \\
Total & 54 & $\mathbf{1 0 0 . 0}$
\end{tabular}

Berdasarkan tabel 1. diatas menunjukan frekuensi berdasarkan usia didapatkan kelompok usia 15 tahun sebanyak 12 responden dengan persentase $(15,4 \%)$, kelompok usia 16 tahun sebanyak 46 responden dengan persentase (59\%), kelompok usia 17 tahun sebanyak 17 responden dengan persentase (21,8\%), kemudian kelompok usia 18 tahun sebanyak 3 responden dengan persentase $(3,8 \%)$. Berdasarkan kelas didapatkan kelas X sebanyak 37 responden dengan persentase $(47,4 \%)$ kemudian kelas XI sebanyak 41 responden dengan persentase (52,6\%). berdasarkan mulai merokok siswa SMK Negeri Tanjungsari Lampung Selatan Tahun 2019/2020 didapatkan paling banyak kurang dari 15 tahun sebanyak 42 responden dengan persentase $(53,8 \%)$, untuk yang mulai merokok diusia lebih dari 15 tahun sebanyak 12 responden dengan persentase $(15,4 \%)$, kemudian kelompok yang yang tidak merokok sebanyak 24 responden dengan persentase (30,8\%). Berdasarkan alasan merokok didapatkan ikut-ikutan teman sebanyak 22 responden dengan persentase sebesar $28,2 \%$, dengan alasan rasa ingin tahu sebanyak 21 responden dengan persentase $26,9 \%$, dengan alasan menghilangkan stress sebanyak 17 responden dengan persentase sebesar $12,8 \%$, dengan alasan terpaksa oleh temannya sebanyak 1 responden dengan persentase 1,3\%. Adapun yang tidak merokok sebanyak 24 responden dengan persentase sebesar 30,8\%. Berdasarkan tipe perokok didapatkan perokok ringan sebanyak 37 responden dengan persentase (47,4\%), perokok sedang sebanyak 17 responden dengan persentase $(21,8 \%)$, kemudian kelompok yang yang tidak merokok sebanyak 24 responden dengan persentase (30,8\%). Berdasarkan lama merokok didapatkan kelompok dengan lama merokok selama $<6$ bulan sebanyak 2 responden dengan persentase (2,6\%), kelompok lama merokok selama 6-12 bulan sebanyak 10 responden dengan persentase (12,8\%), kelompok lama merokok selama $>1$ tahun sebanyak 42 responden dengan persentase (53,8\%) kemudian kelompok yang tidak merokok sebanyak 24 responden dengan persentase $(30,8 \%)$. Berdasarkan hasil analisis 
menunjukkan bahwa frekuensi siswa SMK Negeri Tanjungsari Lampung Selatan Tahun 2019/2020 berdasarkan pengetahuan bahaya merokok didapatkan kelompok dengan pengetahuan kurang sebanyak 16 responden dengan persentase $(20,5 \%)$ kemudian kelompok dengan pengetahuan baik sebanyak 62 responden dengan persentase $(79,5 \%)$. Berdasarkan perilaku merokok didapatkan kelompok dengan perilaku merokok sebanyak 54 responden dengan persentase (69,2\%), kemudian kelompok dengan perilaku tidak merokok sebanyak 24 responden dengan persentase $(30,8 \%)$.

Tabel 2. Hubungan Pengetahuan Dengan Perilaku Merokok Pada Siswa SMK Negeri Tanjungsari Lampung 2020

\begin{tabular}{|c|c|c|c|c|c|c|c|c|}
\hline \multirow{3}{*}{ Pengetahuan } & \multicolumn{4}{|c|}{ Perilaku Merokok } & \multirow{2}{*}{\multicolumn{2}{|c|}{ Total }} & \multirow{3}{*}{ OR } & \multirow{3}{*}{ P value } \\
\hline & \multicolumn{2}{|c|}{ Merokok } & \multicolumn{2}{|c|}{$\begin{array}{c}\text { Tidak } \\
\text { Merokok }\end{array}$} & & & & \\
\hline & $\mathbf{N}$ & $\%$ & $\mathbf{N}$ & $\%$ & $\mathbf{N}$ & $\%$ & & \\
\hline Kurang & 15 & $93.8 \%$ & 1 & $6.3 \%$ & 16 & 100.0 & 8.846 & 0.017 \\
\hline Baik & 39 & $62.9 \%$ & 23 & $37.1 \%$ & 62 & 100.0 & & \\
\hline Total & 54 & $69.2 \%$ & 24 & $30.8 \%$ & 78 & 100.0 & & \\
\hline
\end{tabular}

Berdasarkan hasil uji analisis bivariat menggunakan fisher's exact test pada tabel 3 diperoleh hasil dari 78 responden terdapat 15 orang pengetahuan kurang dengan perilaku merokok $(93,8 \%)$ dan 1 orang pengetahuan kurang dengan perilaku tidak merokok (6.3\%). Kemudian siswa dengan pengetahuan baik dengan perilaku merokok terdapat 39 orang $(62,9 \%)$ dan pengetahuan baik dengan perilaku tidak merokok terdapat 23 orang $(37,1 \%)$. Data ini menunjukkan terdapat hubungan yang bermakna antara pengetahuan dan perilaku merokok di SMK Negeri Tanjungsari Lampung Selatan Tahun 2019/2020 dengan $p$ value : 0,017. Hasil penelitian diatas sejalan dengan penelitian yang dilakukan oleh Jelantik dan Tjindawang (2013) di SMAN 5 Mataram bahwa terdapat hubungan yang bermakna antara pengetahuan remaja tentang rokok dengan kebiasaan merokok. Penelitian Andika (2016) Hubungan Pengetahuan Dengan Kejadian Merokok Pada Pelajar SMPN 1 Pariaman, menunjukkan hasil penelitian pada 228 orang didapatkan responden dengan tingkat pengetahuan baik sebesar $60 \%$ dan kejadian merokok sebesar $1 \%$. Analisis statistik menunjukkan bahwa terdapat hubungan antara tingkat pengetahuan tentang rokok dan kejadian merokok pada pelajar SMPN 1 Pariaman.

\section{Simpulan Dan Saran}

Berdasarkan hasil penelitian maka dapat diambil kesimpulan : bahwa pada penelitian ini memiliki hubungan yang bermakna antara pengetahuan dengan perilaku merokok pada siswa SMK Negeri Tanjungsari Lampung Selatan 2020. Bagi dinas kesehatan melakukan sosialisasi terhadap sekolah-sekolah tentang bahaya merokok dengan memberikan edukasi kepada siswa tentang dampak dari perilaku merokok, lebih ditujukan supaya siswa yang merokok agar berhenti dari kebiasaan merokok. Orang tua dapat memberikan teladan dengan tidak merokok karena perilaku merokok sebagian besar di pengaruhi oleh lingkungan pergaulan dengan teman sebaya dan lingkungan keluarga. Pihak sekolah dapat mengawasi siswa dan memberikan sanksi yang tegas terhadap pelajar yang ketahuan merokok di lingkungan sekolah, selain itu sekolah perlu mengadakan edukasi tentang rokok. 


\section{Daftar Rujukan}

Affandi, V. I. P. (2019). Rokok dan Kejadian Konversi Sputum Pasien Tuberkulosis. Jurnal Ilmiah Kesehatan Sandi Husada, 10(2), 226-232.

Alamsyah, R.M., (2009). Faktor-faktor yang mempengaruhi kebiasaan merokok dan hubungannya dengan status penyakit periodontal remaja di kota Medan tahun 2007 (Master's thesis).

Al Dhuha, S., Setiawati, O. R., Lestari, S. M. P., \& Rukmono, P. (2020). A Kontrol Diri dengan Motivasi Belajar SMA Negeri 1. Jurnal Ilmiah Kesehatan Sandi Husada, 11(1), 190196.

Andika, D., Khairsyaf, O., \& Pertiwi, D. (2016). Hubungan Pengetahuan Dengan Kejadian Merokok Pada Pelajar SMPN 1 Pariaman. Jurnal Kesehatan Andalas, 5(2).

Andriyani, D., (2018). Hubungan Merokok dengan Kebersihan Gigi dan Mulut Siswa SMK di Bandar Lampung. Jurnal Ilmiah Keperawatan Sai Betik, 13(1), pp.83-89.

Anggarwati, A. (2014). Hubungan antara interaksi teman sebaya dengan Perilaku merokok pada remaja (Doctoral dissertation, Universitas muhammadiyah Surakarta).

Dismiantoni, N., Anggunan, A., Triswanti, N., \& Kriswiastiny, R. (2020). Hubungan Merokok Dan Riwayat Keturunan Dengan Kejadian Hipertensi. Jurnal Ilmiah Kesehatan Sandi Husada, 11(1), 30-36.

El Hasna, F.N.A., Cahyo, K. and Widagdo, L., (2017). Faktor-faktor yang Berhubungan dengan Penggunaan Rokok Elektrik pada Perokok Pemuladi SMA Kota Bekasi. Jurnal Kesehatan Masyarakat (e-Journal), 5(3), pp.548-557.

Fitriana, K. R. (2019). Efek Konsumsi Alkohol dan Merokok Pada Wanita Hamil. Jurnal Ilmiah Kesehatan Sandi Husada, 10(2), 233-237.

G. Jelantik, IG Made., Tjindawang, L Dea. (2013). Hubungan Pengetahuan Remaja tentang Rokok dan Interaksi Kelompok Sebaya dengan Kebiasaan Merokok pada Remaja (Studi di SMAN 5). Widyaiswara BPTK Mataram Dinkes Provinsi NTB.

Hurlock, E. B. (2012). Psikologi Perkembangan, Suatu Pendekatan Sepanjang Rentang Kehidupan. Jakarta: Erlangga.

Kementerian Kesehatan Republik Indonesia. (2015). Buku Petunjuk Teknis Konseling Berhenti Merokok Pada Anak Usia Sekolah / Madrasah Bagi Guru Pembina Usaha kesehatan Sekolah / Madrasah (UKS/M). Jakarta: Kemenkes RI.

Kementerian Kesehatan Republik Indonesia. (2015). Perilaku Merokok Masyarakat Indonesia. Infodatin Kemenkes RI.

Kementerian kesehatan. (2012). Aliansi bupati/walikota dalam pengendalian masalah kesehatan akibat tembakau dan penyakit tidak menular

Martini, S., \& Sulistyowati, M. (2005). The determinants of smoking behavior among teenagers in East Java Province, Indonesia.

Riset Kesehatan Dasar (riskesdas) (2018). Badan Penelitian dan Pengembangan Kesehatan kementerian Kesehatan Republik Indonesia tahun 2018.

RISKESDAS. 2013. Laporan Nasional Riskesdas (2013). [Diakses dari www.k4health.org/sites/default/files/laporan Nasional\%20Riskesdas\%202013.p df pada tanggal 26 Maret 2020]

Silowati, L. N. (2012). Hubungan Tingkat Pengetahuan Tentang Merokok Dengan Frekuensi Merokok Pada Remaja Awal Di Desa Gayam Kecamatan Sukoharjo Kabupaten Sukoharjo (Doctoral dissertation, Universitas Muhammadiyah Surakrta).

Suhta, D. W. (2018). Pengetahuan dan Perilaku Merokok Pelajar Sekolah Menengah Pertama. Jurnal Manajemen Kesehatan Yayasan RS. Dr. Soetomo, 4(1), 47-60.

Zaenabu, L. (2014). Hubungan Antara Pengetahuan Tentang Bahaya Rokok Dengan Tindakan Merokok Pada Siswa Sma Negeri 8 Surakarta (Doctoral dissertation, Universitas Muhammadiyah Surakarta 